\title{
SPREADSHEET ANALYSIS AND DESIGN
}

\author{
Boaz Ronen \\ Department of Information Systems \\ Leonard N. Stern School of Business \\ New York University \\ 44 West 4th Street, Suite 9-170 \\ New York, NY 10012-1126 \\ Michael A. Palley \\ Baruch College, CUNY
}

School of Business and Public Administration

17 Lexington Avenue, Box 513

New York, NY 10010

Henry C. Lucas, Jr.

Department of Information Systems

Leonard N. Stern School of Business

New York University

44 West 4th Street, Suite 9-67

New York, NY 10012-1126

June 1987

Working Paper Series

STERN IS-87-52 


\title{
SPREADSHEET ANALYSIS AND DESIGN
}

Boaz Ronen*

Michael A. Palley**

Henry C. Lucas, Jr.*

\begin{abstract}
$\underline{\text { ABSTRACT }}$
Spreadsheet programs and microcomputers have revolutionized information processing in organizations. Users have adopted spreadsheets to solve problems and circumvent the long delays encountered in dealing with the traditional information services department. A significant number of serious errors have been reported through the misuse of spreadsheet technology. This paper discusses several different contexts for the development of spreadsheet models and presents structured design techniques for these models. The recommended approach to spreadsheet analysis and design encourages the use of a block structure format for the worksheet and introduces spreadsheet Flow Diagrams as a systems design tool. The objective of this design approach is to reduce the probability and severity of spreadsheet errors, improve auditability and promote greater longevity for spreadsheet models.
\end{abstract}

* Graduate School of Business Administration, 100 Trinity Place, New York, N.Y. 10006

** Baruch College, CUNY, School of Business and Public Administration, 17 Lexington Avenue, Box 513, New York, N.Y. 10010 


\section{INTRODUCTION}

Spreadsheet programs have become extremely popular with microcomputer users. Spreadsheets are utilized heavily by end users and systems professionals alike. In fact spreadsheet software has contributed a great deal to the popularity of personal computers. These packages present the user with a general purpose problem solving tool.

A spreadsheet can be viewed as a large matrix in which columns are typically designated by letters and rows by numbers. The intersection of a row and column defines a cell; a cell can contain a number, label or formula which relates it to other cells in the spreadsheet. The ability to relate cells with formulae is what provides spreadsheets with their tremendous power. If the spreadsheet model is constructed with formulae, a change in one or two numbers is immediately reflected throughout the spreadsheet.

As an example, consider Figure 1 which is the printout of a simple spreadsheet model. Figure 1 is a salary calculation model; the decisionmaker enters an increase amount, and the percentage of the 1987 wage the increase represents is calculated in the third column. Total increases and the percentage of total 1987 compensation they represent are computed in the Totals row.

Suppose that the decisionmaker is told that wage increases in his department can average $8 \%$ for 1987 . This model allows him to enter different increases for individuals, observe the individual's percentage increase 
and at the same time view the impact of all increases on the "bottom line" represented by the totals. In this instance, the decisionmaker has stopped having reached a departmental aggregate wage increase of $8.03 \%$

once this model has been constructed, the only input needed by the decision maker is to enter dollar amounts in the column labeled "Increase." The alternative to a spreadsheet model is pencil, paper and calculator; each time a new salary increase is entered, the totals must be manually recomputed. One of the authors used to use a calculator for this process and developed the model in Figure 1 as his first spreadsheet application. He reports that the time to figure raises fell by a factor of at least five using the model.

Spreadsheets offer a tremendous amount of analytical power. Most users of spreadsheets develop the models themselves. Another attraction of both microcomputers as well as this type of software is that the user is no longer dependent on the information services staff. Especially for quick, infrequently used applications such as the one in Figure 1 , it would take far too long to create an application on a mainframe or mini through the information services department. Overview

This paper recommends a structured approach to the design of spreadsheet models. Topics covered include the differences between spreadsheets and traditional information 
processing applications. The paper then suggests that different types of design contexts influence the degree of structure appropriate in spreadsheet design. The life cycle of a spreadsheet is presented along with a block structure format for these models. The paper introduces spreadsheet flow diagrams (SFDs) as one approach to designing these models. The paper concludes with suggestions for menu designs for spreadsheets.

\section{DESIGN METHODOLOGY}

\section{The Problem}

Spreadsheet packages and micros have extended computing to vast numbers of individuals. For many users, the spreadsheet program represents the first "hands on" experience with a computing device, programming and documentation. In general, these users have not been trained to undertake systems analysis and tend to overlook the concerns of the professional systems analyst in designing a system, such as reliability, auditability and control. In fact, the spreadsheet user is often happy to avoid systems professionals.

Unfortunately, user independence comes at a potentially high cost. The practitioner literature has discussed a number of problems with spreadsheet construction (Bryan, 1986 and Grushcow, 1985). Examples of frequently cited errors are mistakes in logic, incorrect ranges in formulae, incorrect cell references, confused range names, incorrectly 
copied formulae, incorrect use of formats and column widths, accidentally overwritten formulae and misuse of built-in functions. Table 1 describes some of the problems found with spreadsheets.

\section{Design Objectives}

To minimize the probability and severity of the problems in Table 1, the designer of a spreadsheet should be concerned with the following issues: 1) A spreadsheet should produce reliable results; the output it generates should be correct and consistent. 2) A spreadsheet should be capable of being audited; the user should be able to retrace the steps followed to generate different outputs from the model to understand the model and to verify findings. 3) A spreadsheet should be capable of being modified easily without introducing errors.

A final issue impacts the three listed above: comprehensibility. The designer and user should be able to easily understand the model and its assumptions as represented in the spreadsheet. Spreadsheets and Traditional IS

Spreadsheets are a type of information system, though they are most often not developed by information systems professionals. The Is professional is (or should be) concerned with the issues described above in designing any information system. One reason for lengthy development times for multiuser systems designed by professionals is 
concerns about data integrity, input editing and error checking.

Since the spreadsheet developer is often a user who is basically unfamiliar with the design principles above, ad hoc design is common. There tends to be little concern with formal analysis or documentation. Often the spreadsheet model is a one-time exercise or an infrequently used decision support system (DSS). Formal design methods slow progress on "quick" systems.

A structured approach to spreadsheet design can help reduce the probability and severity of problems with spreadsheets. To be useful, a spreadsheet design approach must help achieve the objectives for these models described above, must achieve results quickly, and must be suited to the style of the end user. Table 2 describes the characteristics of spreadsheet applications and the implications of these characteristics for design.

Because of the wide variety of use for spreadsheet models, it is very difficult to construct a design methodology that will be generally applicable. This paper proposes a structured approach to design the use of which is contingent on the type of model being developed.

\section{SPREADSHEET ANALYSIS AND DESIGN}

Types of Applications

Spreadsheets are distinguished by the variety of applications for which they have been used. The most 
frequent use of spreadsheets is for decision support and personal productivity, but there have also been many spreadsheet applications which could be considered mainstream information systems applications. For example, a firm might do all of its financial statement consolidation for its subsidiaries using a spreadsheet package. Before this software was available, the firm might have written COBOL programs or purchased a dedicated package to produce financial statements.

Figure 2 depicts the design context for spreadsheets. If the spreadsheet is to be used for a traditional transactions processing or information processing task, then one could argue that it should be designed using normal information services methodologies like structured design, data flow diagrams, etc.; (see Lucas, 1985). However, it is unlikely that such formal design will be used. The techniques presented below are an alternative to completely informal, ad hoc design for systems professionals as well as end users.

In the DSS environment, it is important to consider whether or not the developer is also the user. If the user develops his or her own model for a one shot decision, then informal design procedures are probably satisfactory. It is also unlikely that anyone can convince the user in these circumstances to adopt any other approach! If the one-shot decision is crucial to the organization, it might be useful 
to at least have someone other than the designer audit the model.

If a user is developing his or her own application and plans to use it frequently, then the analysis approach suggested later in this paper should be considered. When the developer is not the primary user, then it is recommended that a formal design methodology be employed. Even if the system is to be used for a one-shot decision, the fact that the spreadsheet is being designed for someone else suggests that the decision is either very important or the model is complex; either condition warrants the use of a formal approach to design.

Appplications that will be used frequently by many users are candidates for formal design, macros and menus. If users are experienced and understand the package, macros and menus may be an extra option. However, if users are inexperienced, menus and macros are needed to help the user execute the model and to protect the spreadsheet.

\section{The Spreadsheet Development Life Cycle}

Texts on systems analysis and design usually include a systems development life cycle. (See Lucas, 1985.) It is possible to develop a similar life cycle for spreadsheet applications, though the life cycle must be flexible to reflect the different contexts for spreadsheet design described above. (See Figure 3.) 
1. Problem Identification

The designer defines the nature of the problem to be solved. How is the problem currently solved if at all? What are the performance bottlenecks? This stage is similar to the "existing systems study" of the systems development life cycle. How will a spreadsheet model help solve the problem? What are the sources of information?

a. Cost benefit analysis.

What is a reasonable time frame for model development? What kind of application is this, e.g. is it a one-shot decision model or a model that will be used many times? What resources should be put into development? b. "Make or buy" analysis. The designer should conduct research to determine if an existing template can be purchased for this application. There are a number of such templates for income tax calculations, rental analysis, real estate investments, etc.

2. Definition of model outcome/decision variables.

The spreadsheet is usually developed to produce some type of results like a net present value for an investment, a yearly estimate of profits, the deviation of actual from budgeted expenses, or a set of financial statements. The outcome variable needs to be defined. The designer may have variable which represents a decision such as the dollar raises granted to each employee in Figure 1. 
a. Define how the outcome is generated.

This part of the model represents the calculations which are undertaken in the model.

b. Define the block structure of the model.

A recommended model structure is presented later in this paper.

c. Define menus/macros (optional)

If the model will have menus and macros, the designer should describe their function at this point.

3. Construct the model

This stage corresponds to the traditional notion of programming. Using the various commands of the spreadsheet language, build the model. When the model is large, use a top down approach in which building blocks are constructed and then filled in with details.

a. Build macros and menus (optional)

Depending on the type of applications, the developer may want to include menus and macros.

4. Test

Carefully test the results of the model. Print a hard copy of the model and the cell formulae. Check all calculations independently from the spreradsheet. Test both historical and extreme input data. Examine the spreadsheet to see if there is an audit trail; can someone follow through the assumptions to determine how a cell's value was determined, or is too much hidden in formulae? Look for 
formatting errors which might result in the unintentional rounding of percentages or multipliers.

5. Documentation

Document the spreadsheet on the spreadsheet, itself. That is, include text on the spreadsheet that explains the model as shown later in the paper.

6. Audit

Review the model and its structure. Consider the use of audit packages to trace through formulae.

7. Prepare a user manual (optional)

For systems designed for others to use, a manual is a necessity. For applications created by the user, a manual is valuable if the application is to be used more than once. 8. Training (optional)

If the model is to be used by others, they need to be trained prior to installation.

9. Installation.

Prepare the spreadsheet for use, for example, by installing it on a users computer so that the model loads whenever the spreadsheet program is started.

The next section of this paper suggests a block structured format for a spreadsheet model. Then the paper introduces the concept of Spreadsheet Flow Diagrams as a structured design aid. Finally, the paper concludes with a discussion of how to design menus for spreadsheets. 
Model Format

Figure 4 presents a recommended structure for a spreadsheet. Similar designs have been proposed in Grupe (1985) and Berry (1985). The purpose of the structure is to separate parts of a spreadsheet into blocks to reduce the potential for errors. A well structured spreadsheet also clarifies the assumptions of the model to users.

Figure 4 contains a number of blocks which taken together comprise the spreadsheet model. The identification block presents the name of the developer, user and the name of the model. It also contains a list of revision dates. To the right of the identification block one finds the macros/menus block. Macros and menus must be isolated from parameters and formulae because the insertion or deletion of a row in a model could delete a line or insert a blank line in a macro causing quite anomalous behavior when the macro is executed.

Immediately below the identification block is a map or index to the spreadsheet. It contains a description of where the various blocks may be found and acts like a table of contents for the model.

The large documentation block allows the spreadsheet developer to describe in general terms how the model works and to annotate various rows in the model, itself.

The parameter block contains variables which are used in the formulae. For example, one would place interest rates, assumptions about sales growth rates, and so on in 
the parameter block. A good rule to follow is that no formula should contain a number; there should only be references to parameters or cells in the worksheet. If this rule is followed, there is little danger of misinterpretation because a crucial parameter is hidden in a formula. Looking over multiple runs of the model, the user will be able to see what assumptions pertain to each run, for example, it will be clear what interest rate was used on each model run by examining the parameter block for the interest rate parameter.

The final block in the spreadsheet is the model, itself. The spreadsheet packages with their row and column references suggest a view of the model as a matrix. Certain columns or rows of the matrix (possibly a single cell) might be interpreted as input or output vectors.

\section{Spreadsheet Flow Diagrams}

The notion of Data Flow Diagrams (DFD) has proven popular in traditional systems analysis and design as a way to encourage structured, top down design and to reduce complexity (Gane and Sarson, 1979, DeMarco, 1979). This paper proposes the use of Spreadsheet Flow Diagrams (SFD) for the analogous purpose with spreadsheets. For many spreadsheets there will be no need to follow a top down approach because the model will be simple. However, for large spreadsheets, the notation allows and encourages the use of top down design approaches. 
Why not just use existing DFD notation? DFDs were designed for transactions processing systems; they are excellent for showing sources, flows and processing of data. The spreadsheet is less concerned with the flow of data than it is with modeling relationships. Even a low level DFD might only indicate "Post Receivables" to denote a process that most designers and users would understand. spreadsheet analysis and design needs a notation that shows the "algorithm" or the underlying formulae of the model.

Figure 5 shows the basic symbols of SFDs. A simple rectangle is used to represent input vectors, output vectors, decision vectors and parameters. (Any of these vectors can be a scalar if it contains only one value.) The type of vector is designated by a $45^{\circ}$ line on one corner of the rectangle as shown in Figure 5. A rounded rectangle represents the formulae in the model.

It should be noted that the input, decision and outcome vectors are subsets of the model matrix in most instances. Some examples will show these unique characteristics of spreadsheet models and will also demonstrate how the SFDs can be used in design and documentation.

In Figure 1, the input, decision and outcome vectors are highlighted. They constitute three of the four columns in the matrix that is the model. An SFD for the salary increase model in Figure 1 may be found in Figure 6a. The SFD shows clearly that the increase is the decision variable and that the outcome is to be a salary figure for 1988 . 
While this decision vector may seems obvious, approximately $50 \%$ of students assigned this problem end up using the percentages as the decision vector and awarding raises like $\$ 2432$ !

Figure 7 presents a typical spreadsheet application for predicting sales of a new product and Figure $6 \mathrm{~b}$ is a high level SFD for the model. The input vector has a subscript "t" to show that the model is predicting values over a time period. Because it is easier to understand, the model diagram shows profits as being sales less expenses. The model box (labeled 1 ) in Figure $6 \mathrm{~b}$ is exploded into a lower level of detail in Figure 6c.

Figure 8 contains the final example, a grading program; the corresponding SFD may be found in Figure $6 \mathrm{~d}$. Here there are $\mathrm{m}$ students with $\mathrm{n}$ grades. The model weights the grades to provide a final average and grade for each student. The instructor also is interested in the mean, variance and standard deviation of the scores on each assignment. The subscripts $m$ and $n$ used in the SFD clarify the requirements of the model.

The advantage of using a structured notation for spreadsheets is the same as the advantage of using a notation like Data Flow Diagrams for traditional systems analysis and design. SFDs help the designer structure the design of the problem. They assist in communicating the structure of a model to others and they serve as 
documentation when it is necessary to audit or modify the spreadsheet.

\section{Menu Design}

Many popular spreadsheet packages allow the model developer to define macros (programs consisting of keystrokes) and menus. Figure 9 is an example of a statetransition diagram for a menu for the grading program in Figure 8. Each keystroke selection from the main menu moves the user to a state represented by one of the circles. In Figure 9, the menu appears as the spreadsheet is loaded. The user sees a menu which contains the following commands: Add, Delete, Modify, Print, Save and Quit. Typing the letter $A$ results in the execution of a spreadsheet macro to add a student to the roster.

If there were submenus reached from this first level, they could be shown in a similar fashion. For example, suppose that modify allows the user to choose what is to be modified, a name or a grade. Entering $\mathrm{N}$ results in positioning the cursor in the name column while a grade change places the cursor at the first assignment from which the user can move it to any assignment for any student. The designer has made a decision to return to the modify menu at the completion of a change in anticipation of another change. Alternatively the designer could choose to return to the main menu.

Another alternative to state-transition diagrams is the menu trees often printed for menu-driven packages. These 
menu trees look like organization charts and communicate the same information as found in Figure 9. However, they are less clear about the return point from each command issued than the state-transition diagram.

\section{SUMMARY}

This article has argued for greater structure and care in the design of spreadsheet information systems. The paper first explored some of the problems with spreadsheet design and the differences between the design of traditional information processing applications and spreadsheet models. The major contribution of this research are the following:

1. Guidelines for differing levels of formal design and the appropriate use of menus and macros in spreadsheet design.

2. A suggested systems development life cycle for spreadsheets.

3. A block-structured format for spreadsheet models.

4. Spreadsheet Flow Diagrams.

5. Menu and macro design aids.

Spreadsheet packages have made a major contribution to analysis and problem solving. The importance of the decisions entrusted to spreadsheet modeling and the pervasive use of these packages suggests that end users and developers of these models need to be concerned with good practice in spreadsheet analysis and design. 


\section{REFERENCES}

Ahituv, N. and Neumann, S. (1985). Information Systems for Management, Dubuque, Iowa: Wm. C. Browne, Second Edition.

Ariav, G. and Ginsberg, M. (1985). "DSS design, a systematic view of decision support", Communications of the ACM, 28, 10, pp. 1045-1052.

(1986). "Methodology for DSS analysis and design: a contingency approach to their application", proceedings of the International Conference on Information Systems.

Berry, T. (1986). "How to structure spreadsheets", Business Software, October, 1986, pp. 56-58.

Bryan, M. (1986). "Are your spreadsheets lying to you?", Business Software, October, 1986, pp. 59-64.

Demarco, T. (1979). Structured Analysis and System Specification. Englewood cliffs, Prentice Hall.

Gane, C, and T. Sarson. (1979). Structured Systems Analysis. Englewood cliffs, Prentice Hall.

Grupe, F. (1985). "Tips for better worksheet documentation", Lotus, August, 1985, pp. 68-70.

Grushcow, J. (1985). "Avoid these common spreadsheet errors", Lotus, July, 1985, pp. 59-62.

LeBlond, G. and D.Cobb (1986). Using 1-2-3. Indianapolis, IN: Que Corporation, Second Edition.

Lucas, H.C., Jr. (1985). The Analysis, Design, and Implementation of Information Systems, 3rd. ed., New York: McGraw

-Hill.

McGrath, J. (1986). "PC's can't add - but you can teach them to", Business Software, september, 1986, pp. 58-59. 
Problem

Reliability

Auditability

Modifiability
Description

The degree that the spreadsheet generated output is correct-impact on degree of confidence user places in the model

The ability to retrace the steps followed in the generation of spreadsheet results

The ability to change or enhance the spreadsheet to meet dynamic user requirements

Problems Associated with the

Lack of a Design Methodology

Table 1 


$\begin{array}{lll}\text { Attribute } & \text { Spreadsheets } & \text { Implications } \\ \text { Users } & \begin{array}{l}\text { Non professional } \\ \text { users often are } \\ \text { designers of } \\ \text { spreadsheets }\end{array} & \begin{array}{l}\text { User does not realize } \\ \text { problems with ad hoc } \\ \text { approaches } \\ \text { Assumes no need for } \\ \text { a methodology }\end{array} \\ \text { Development } & \text { Relatively Short } & \begin{array}{l}\text { Attitude of no need } \\ \text { or no time for } \\ \text { a formal approach }\end{array} \\ \text { Modifiability } & \text { Easy } & \begin{array}{l}\text { May convince user to } \\ \text { disregard formal } \\ \text { analysis }\end{array} \\ \text { Life cycle } & \text { Short } & \begin{array}{l}\text { Formal techniques seen } \\ \text { as useless }\end{array} \\ \text { Context } & \text { variety of } & \begin{array}{l}\text { Difficult to build a } \\ \text { methodology suitable to } \\ \text { all contexts }\end{array}\end{array}$

Characteristics of Spreadsheet Analysis and Design

Table 2 
Identification

Owner: John Johnson

Developer: Feter Green

User: Betty Larson

Date: Jan 30, 1987

Revised: Feb. 121987

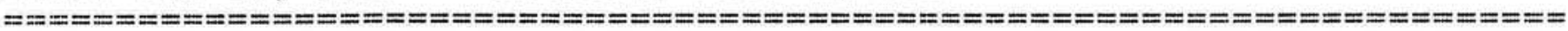

Map of Model

Identification

Map

Fararieters and assumptions

Model

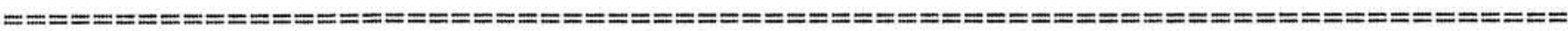

Farameters and Assumptions

1. Current salaries (Input Vector) are given in column B.

2. Salary increase (column c) is the Decision \& the Farameter Vectar.

3. The recommended salary (column E) presents the Output Vectar.

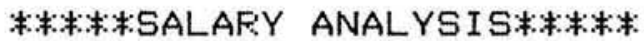

\begin{tabular}{|c|c|c|c|c|}
\hline Name & $\begin{array}{r}\text { Current } \\
1987\end{array}$ & Increase & Fercent & $\begin{array}{r}\text { Recommend } \\
1988\end{array}$ \\
\hline $\begin{array}{l}\text { Jane Doe } \\
\text { Mary Roe } \\
\text { Sam Smith } \\
\text { Peter Jones } \\
\text { Harold White } \\
\text { Steve Black } \\
\text { Marvin Gardens } \\
\text { Betty Boop }\end{array}$ & $\begin{array}{l}\$ 60,000 \\
\$ 50,000 \\
\$ 55,000 \\
\$ 70,000 \\
\$ 65,000 \\
\$ 50,000 \\
\$ 45,000 \\
\$ 56,000\end{array}$ & $\begin{array}{l}\$ 4,000 \\
\$ 4,000 \\
\$ 3,000 \\
\$ 5,500 \\
\$ 4,000 \\
\$ 5,000 \\
\$ 3,500 \\
\$ 7,200\end{array}$ & $\begin{array}{r}E . E 7 \% \\
8.00 \% \\
5.45 \% \\
7.86 \% \\
6.15 \% \\
10.00 \% \\
7.78 \% \\
12.86 \%\end{array}$ & $\begin{array}{l}\$ 64,000 \\
\$ 54,000 \\
\$ 58,000 \\
\$ 75,500 \\
\$ 69,000 \\
\$ 55,000 \\
\$ 48,500 \\
\$ 63,200\end{array}$ \\
\hline Totals & $\$ 451,000$ & $\$ 36,200$ & $8.03 \%$ & $\$ 487,200$ \\
\hline
\end{tabular}

Salary Computation Model

Figure 1 

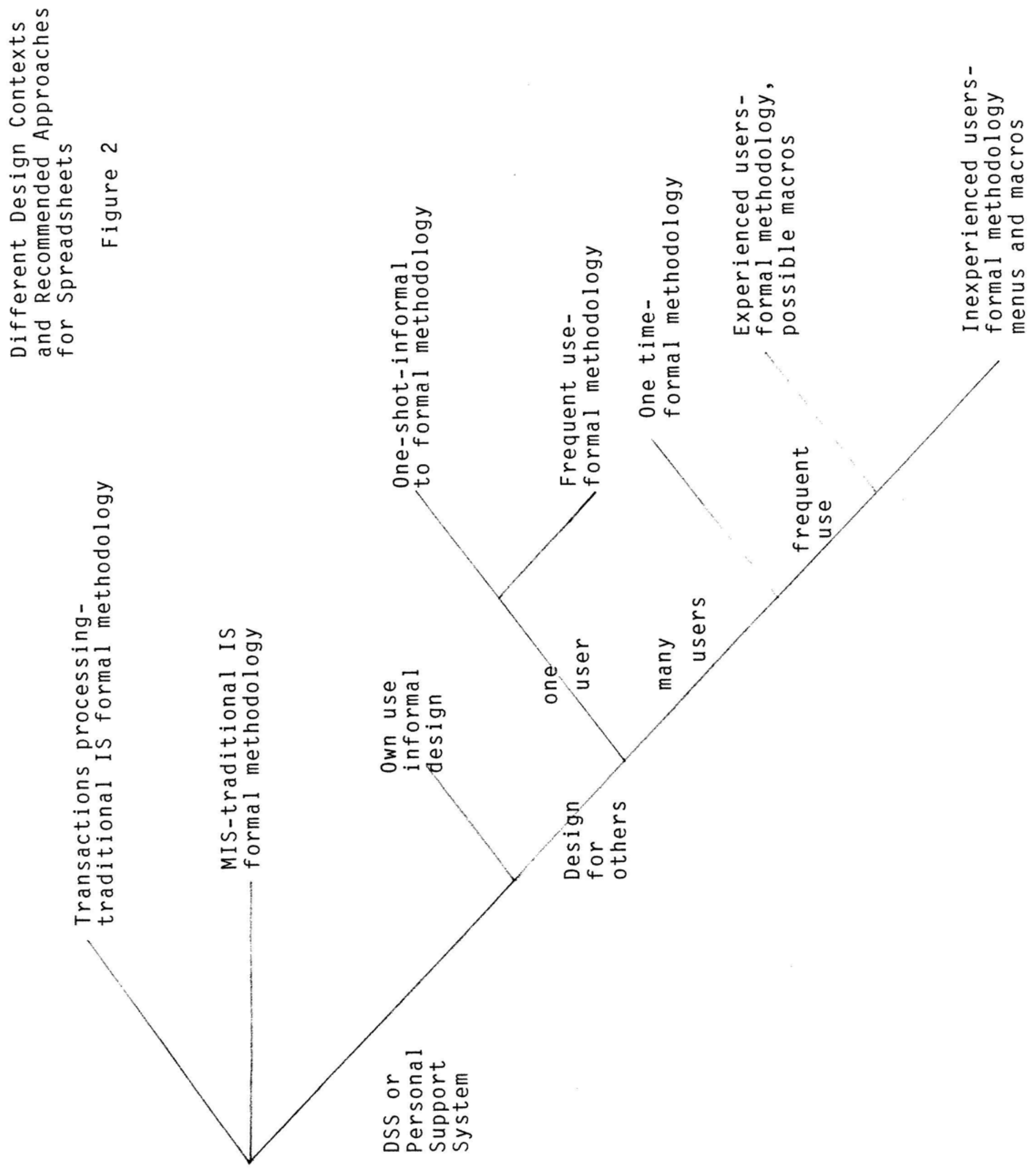

U $\rightarrow$

공ㅇㄴ 의

○ㄴ 0 (1) 음 들 (1) 음 Cᄂ (1) 更 n ه ᄃ 0 屯

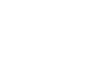


The Speadsheet Development Life Cycle

Figure 3

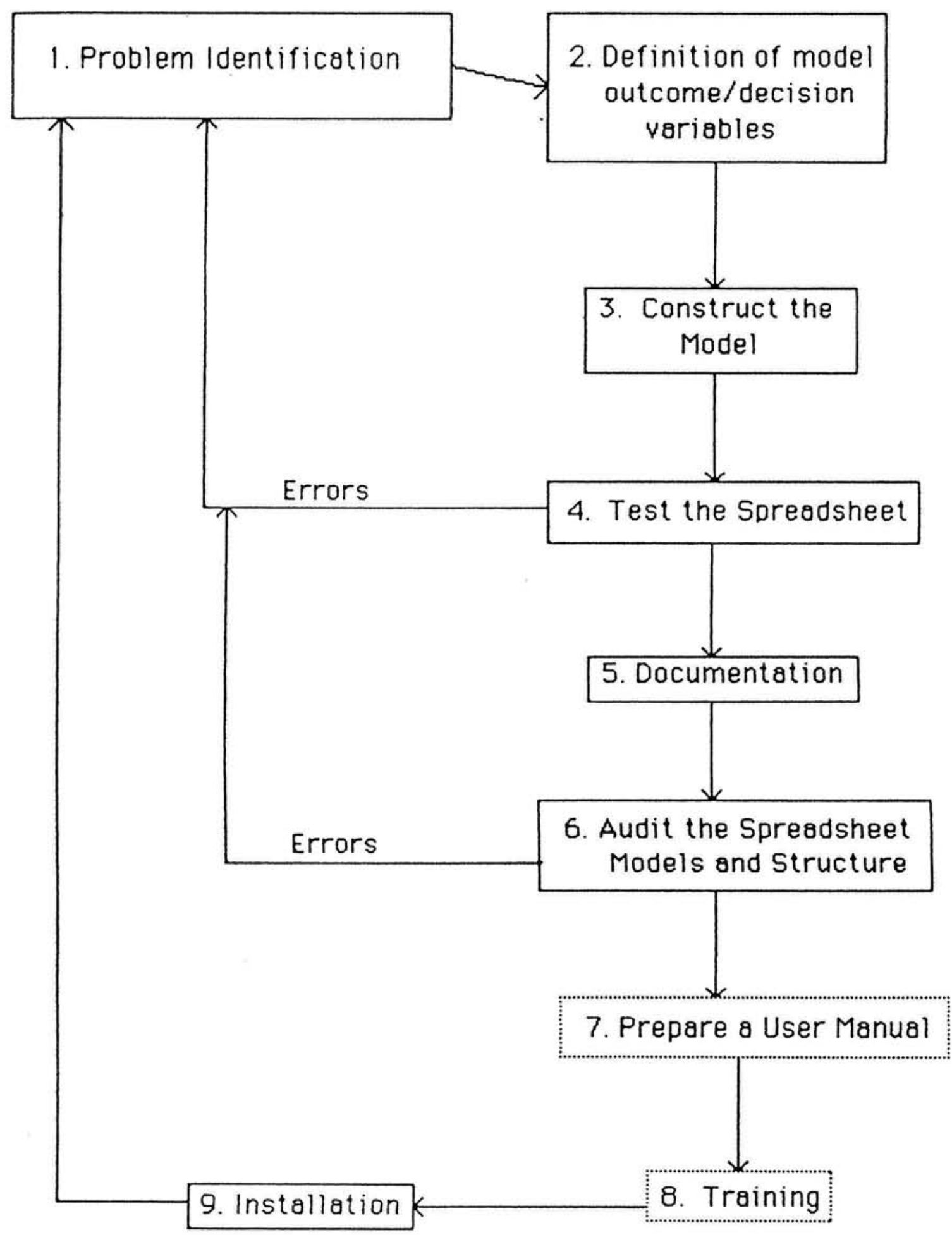




\begin{tabular}{|c|c|c|c|}
\hline $\begin{array}{r}\text { Ident } \\
\text { Owr } \\
\text { De } \\
\text { Us }\end{array}$ & $\begin{array}{l}\text { ication } \\
\text { oper }\end{array}$ & \multirow{2}{*}{\multicolumn{2}{|c|}{$\begin{array}{l}\text { Macros } \\
\text { Menus }\end{array}$}} \\
\hline Date & Revised & & \\
\hline \multicolumn{4}{|c|}{ Map of model } \\
\hline \multicolumn{3}{|c|}{$\begin{array}{l}\text { Parameters } \\
\text { (Assumptions) }\end{array}$} & \\
\hline \multicolumn{3}{|c|}{$\begin{array}{l}\text { Model } \\
\text { Formulae/Matrix } \\
\text { Input Vector(s) } \\
\text { Decision Vector(s) } \\
\text { Parameter Vector (s) } \\
\text { Output Vector(s) }\end{array}$} & \\
\hline
\end{tabular}

Recommended Spreadsheet Structure

Figure 4 


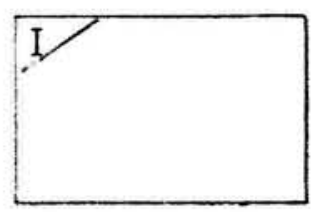

Input Vector

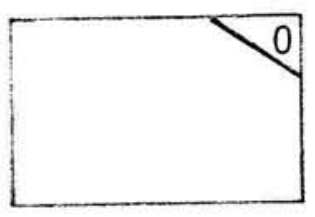

Output Vector

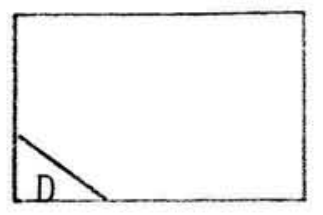

Decision Vector

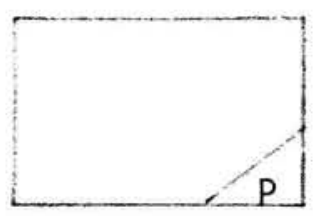

Parameter Vector

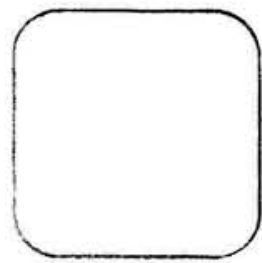

Formulae (Model)

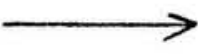

Data Flow

Spreadsheet Flow Diagram Symbols

Figure 5 


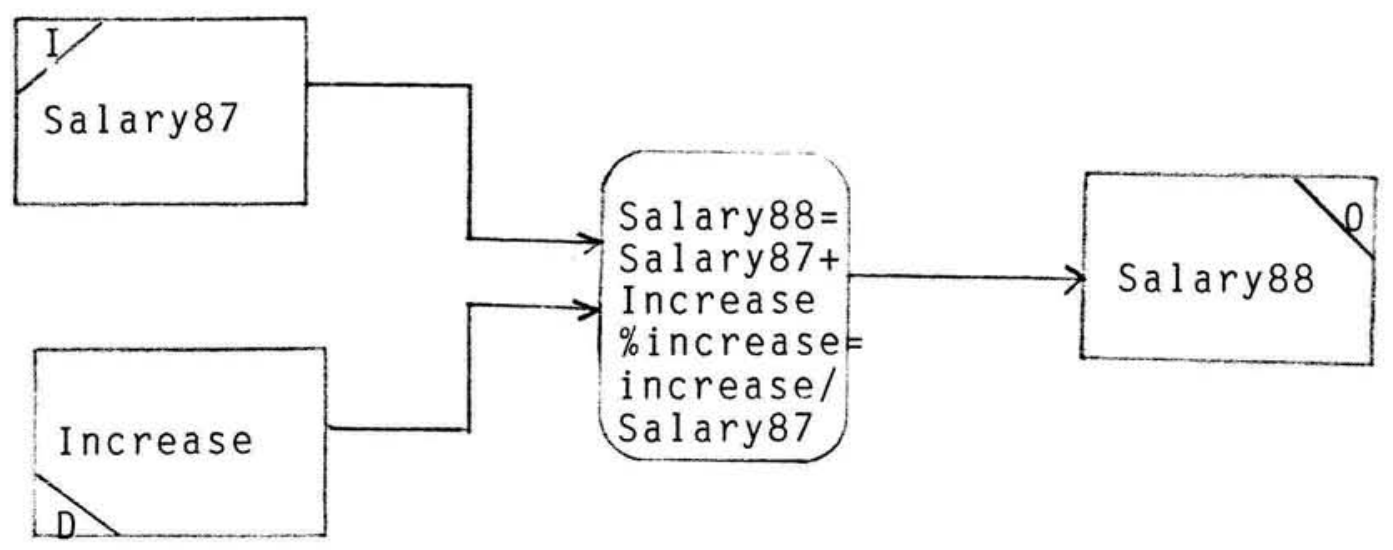

SFD Problem 1

Figure $6 a$ 


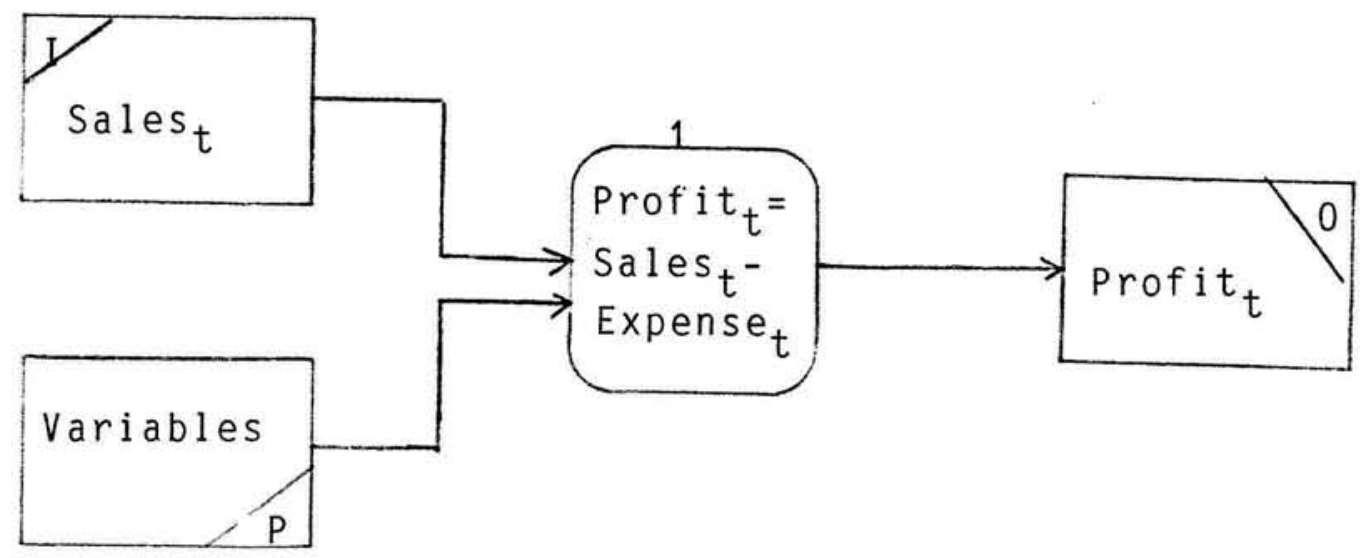

SFD Problem 2

Figure $6 \mathrm{~b}$

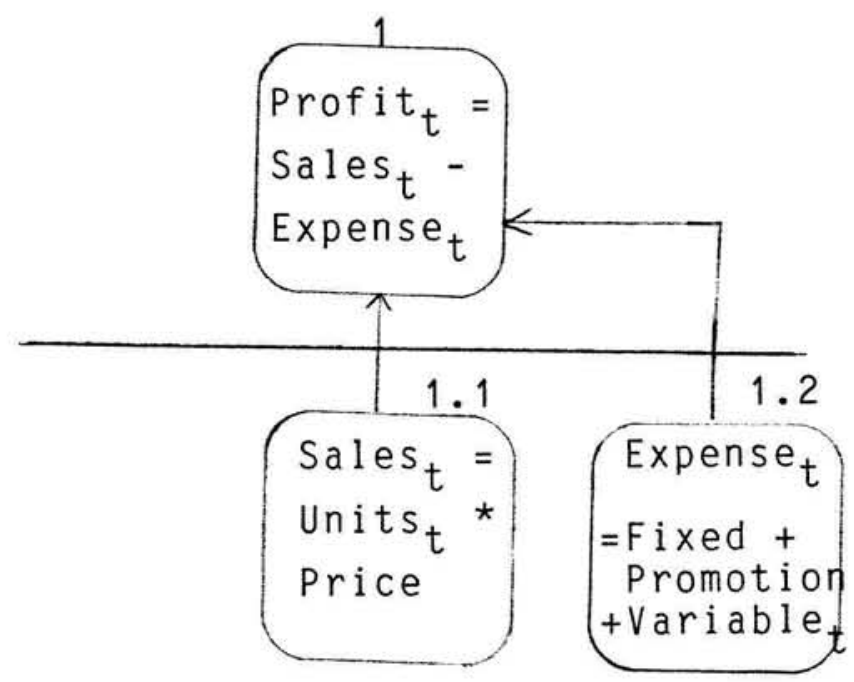

Level 2 SFD for Problem 2

Figure 6c 


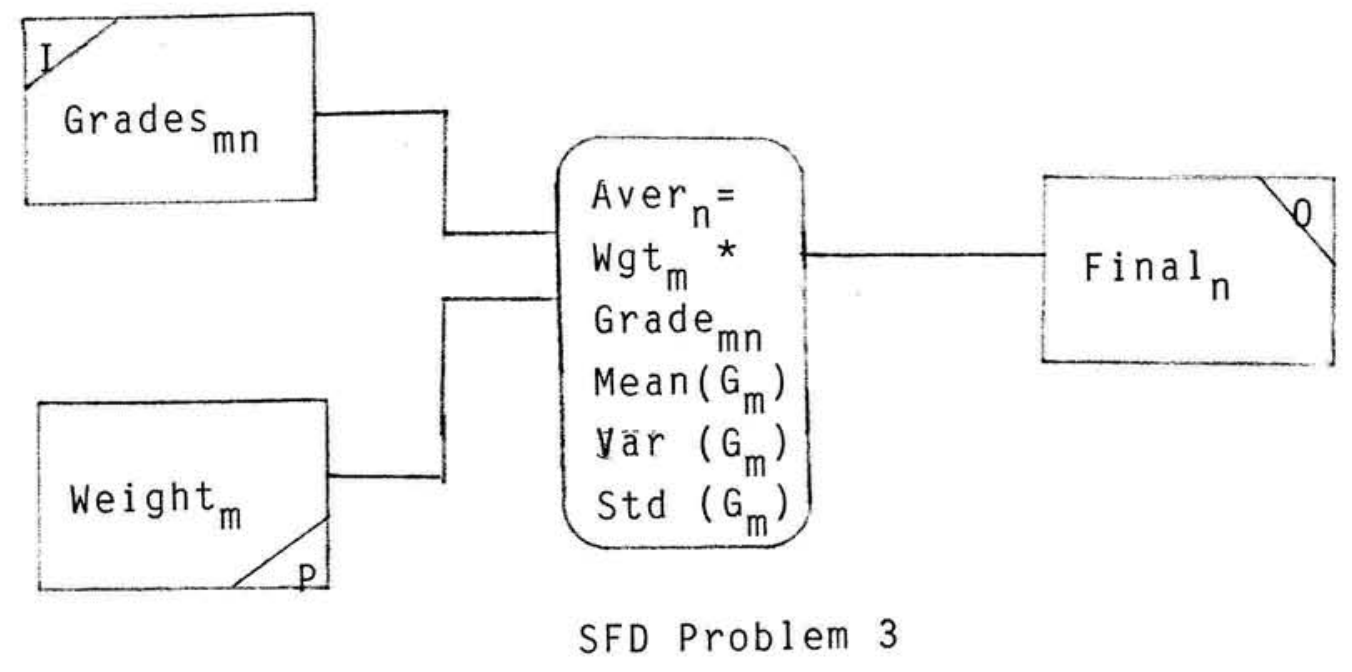

Figure 6d 


\section{Figure 7}

ALL PURPOSE MORKSTATION SOFTHARE CO. \$*\$Nev Product Projections\$\$*

\section{Identification}

Ouner: All Purpose Horkstation Softuare Co.

Developer: Anne Saith

User: Jerry Broun

Date: $2 / 1 / 87$ Revised: $4 / 1 / 87$

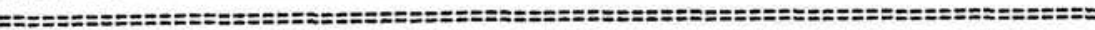

Map of Model

Identification

Map of Model

Parameters and assunptions

Variables

Model

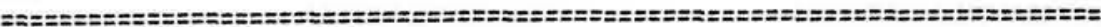

Assuaptions

1. Sales (in units) for 1988 is the Input Vector.

2. The Output Vector is the Net Profit and Net Present Value.

3. The Model Parameters are presented in the Paraneters Box

4. Sales Grouth is considered the same in each year.

5. The interest rate (cost of capital) is fixed during all the period

6. Variable costs are proportionally linear to the nuber of units sold.

7. Tax rate is flat for all profits.

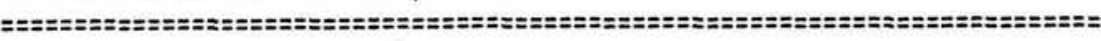

*** Parameter $5 * *$

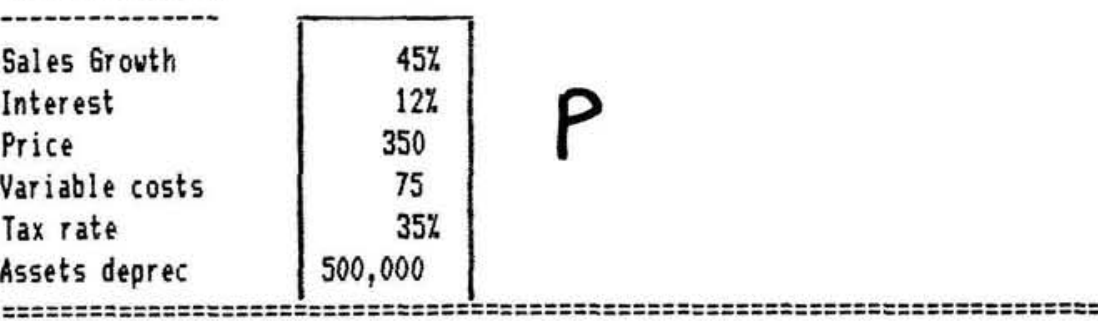
The Model

\begin{tabular}{|c|c|c|c|}
\hline & & \multicolumn{2}{|c|}{ ***Nev Product Projections**** } \\
\hline & 1988 & 1989 & 1990 \\
\hline Sales (units) & 5,000 & I 7,250 & 10,513 \\
\hline Revenue & $\$ 1,750,000$ & $\$ 2,537,500$ & $\$ 3,679,375$ \\
\hline Variable cost & $\$ 375,000$ & $\$ 543,750$ & $\mathbf{5 7 8 8 , 4 3 8}$ \\
\hline Fixed cost & $\$ 900,000$ & $\$ 900,000$ & $\$ 900,000$ \\
\hline Promotion & $\$ 1,000,000$ & $\$ 1,000,000$ & $\$ 1,000,000$ \\
\hline Gross Profit & $(\$ 525,000)$ & $\$ 93,750$ & $\$ 990,938$ \\
\hline Depreciation & $\$ 25,000$ & $\$ 25,000$ & $\$ 25,000$ \\
\hline Taxes & so & $\$ 24,063$ & $\$ 338,078$ \\
\hline Net Profit & $(\$ 550,000)$ & $\$ 44,688$ & $\$ 627,859$ \\
\hline & & $\begin{array}{r}\text { NPV } \\
\$ 540,425\end{array}$ & \\
\hline
\end{tabular}


Figure 8

\$****Student Grading Progran**\$*

Identification

Ouner: Jo Little

Developer: Harry Broun

User: Dr. Dolittle

Date: $2 / 3 / 87$ Revised: $3 / 3 / 87$

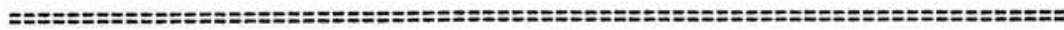

Map of the Spreadsheet

Identification iHacros

Map i

Assunptions

Paraneters

Model

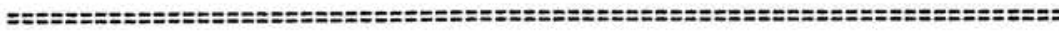

Assuaptions and Paraneters

1. Each assignaent is veight as per Table 1.

2. Grades are assigned per Table 2.

To use the Model:

Alt $M$ starts the acro execution and is the nane of XM

BEGIN is the first student name

START is a range nawe for the wenu

GRADE is a range nane for the grading table

TABLE 1: HEIGHTS

\begin{tabular}{|c|c|c|c|c|c|}
\hline \multicolumn{6}{|l|}{ 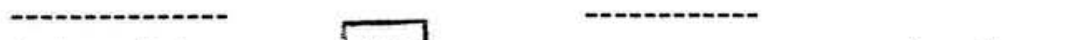 } \\
\hline Assignment 1 & $25 \%$ & & -1 & $\mathbf{F}$ \\
\hline Assignment 2 & $35 \%$ & & 0.01 & 0 \\
\hline \multirow[t]{4}{*}{ Assignment 3} & $40 \%$ & \multicolumn{2}{|c|}{1 std below } & 2.20 & C \\
\hline & & \multirow{2}{*}{\multicolumn{2}{|c|}{$\begin{array}{l}\text { Mean } \\
1 \text { std above }\end{array}$}} & 2.90 & B \\
\hline & & & & 3.60 & A \\
\hline & & & & 4.00 & A \\
\hline \multicolumn{6}{|c|}{ 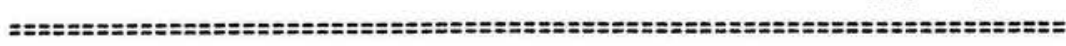 } \\
\hline \multicolumn{6}{|l|}{ The Model } \\
\hline & \multicolumn{5}{|c|}{$\$ * * * *$ Student Grading Progran $* * * * *$} \\
\hline Nane & Assign 1 & Assign 2 & Assign 3 & Course & Final \\
\hline & & & & 0.00 & $\mathrm{~F}$ \\
\hline Boop, Betty & 2 & 2 & 2.3 & 2.12 & $D$ \\
\hline Caroline, Princ & 2 & 1.7 & 3.3 & 2.42 & C \\
\hline Carson, Kit & 3.7 & 3.3 & 4 & 3.68 & A \\
\hline Doe, John & 2 & 2.3 & 2.7 & 2.39 & C \\
\hline Dupris, Jean & 3 & 2 & 3.3 & 2.77 & C \\
\hline Field, Marshall & 4 & 3.7 & 3.3 & 3.62 & A \\
\hline Jones, Betty & 3 & 4 & 3.7 & 3.63 & A \\
\hline HcDonald, Ronal & 3 & 2 & 4 & 3.05 & B \\
\hline Newnan, Alfred & 4 & 4 & 3.7 & 3.88 & A \\
\hline Pan, Peter & 3.7 & 3.7 & 3.7 & 3.70 & A \\
\hline Roe, hary & 1.7 & 2 & 2.3 & 2.05 & $D$ \\
\hline Rogers, Roy & 2.7 & 3.3 & 3.7 & 3.31 & B \\
\hline Suith, San & 2 & 3.3 & 2.7 & 2.74 & C \\
\hline Square, Harold & 1. & 1 & 2.3 & 1.52 & D \\
\hline VanPelt, Lucy & 3 & 2.7 & 2.3 & 2.62 & $C$ \\
\hline Mean & 2.72 & 2.73 & 3.15 & $\overline{2.90}$ & \\
\hline Variance & 0.77 & 0.83 & 0.40 & 0.49 & 0 \\
\hline Standard Deviat & 0.88 & 0.91 & 0.63 & 0.70 & \\
\hline
\end{tabular}

TABLE 2: GRADES 


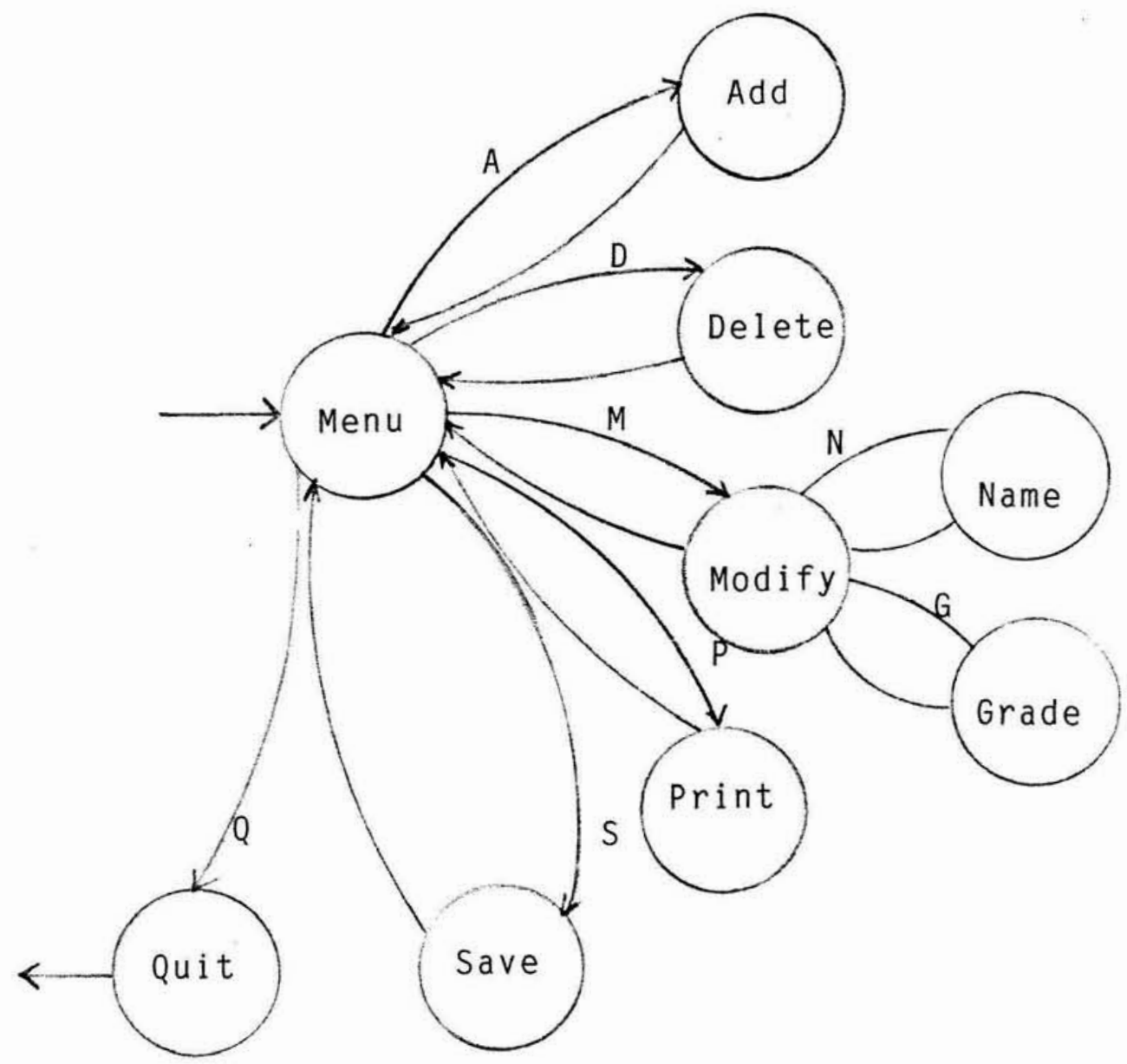

State-Transition Diagram for Menu Design

Figure 9 